\title{
EFFECT OF ZINC OXIDE LEVEL AS ACTIVATOR ON THE MECHANICAL PROPERTIES OF NATURAL RUBBER COMPOSITE
}

\author{
M. N. Chukwu ${ }^{1,}{ }^{*}$, I. Ekhator ${ }^{2}$ and L. O. Ekebafe ${ }^{3}$ \\ 1, 2. 3 Department of Polymer Technology, Auchi Polytechnic, Auchi, Edo State, Nigeria \\ E-mail addresses: ${ }^{1}$ mnchukwu96@gmail.com, ${ }^{2}$ ekhator2007@yahoo.com, \\ 3 lawekebafe@gmail.com
}

\begin{abstract}
The effect of Zinc Oxide level as an activator on the Mechanical properties of Natural Rubber Composite was studied. It has been discovered that technicians usually add additional Zinc oxide different from the recommended dosage used in the formulation receipt during the process of compounding and also recovery of scorched compounds. One hundred parts per hundred rubber (100phr) of Natural rubber was compounded with Zinc Oxide levels of, 0, 2, 3, 4, 5, 6, 7, 8, 10phr respectively. The effect of Zinc Oxide level on tensile strength, elongation at break, modulus, hardness, abrasion resistance and compression set were investigated. The result obtained showed that as the Zinc Oxide level increased, the tensile strength, elongation at break, modulus, hardness and compression set attained their maximum values at 5.0 phr, after which there was a gradual decrease of same properties as a result of reversion. For the purpose of hardness and enhanced tensile properties, a known quantity of 5.0phr is recommended.
\end{abstract}

Keywords: Activator, Composite, Mechanical properties, Natural Rubber, Zinc Oxide.

\section{INTRODUCTION}

Natural rubber irrespective of its excellent properties cannot be used in most engineering applications except they are modified by incorporation of some additives that transforms it into a useful engineering material. Products of desired application are prepared by formulating and compounding the rubber with additives that transform them into useful products. These additives include vulcanization agents, accelerators, activators, fillers, process aids and other miscellaneous ingredients as may be desired by application, processing or service requirements.

Zinc Oxide in conjunction with stearic acid serves as activator in the vulcanization system to increase the efficiency of the accelerators during vulcanization process. The use of Zinc Oxide in conjunction with accelerator has a pronounced effect on the speed and efficiency of vulcanization and on the distribution of crosslink formed [1].

Every ingredient used in rubber compounding has a specific function they perform either in the processing, vulcanization or in end use requirement of the product. Hence Zinc Oxide in conjunction with stearic acid acts as activator to activate the vulcanization process. The essence of activating the vulcanization process is that sulphur acting on its own alone during vulcanisation is a very slow process; hence the essence of activating the vulcanization process is to increase the speed of vulcanization and also the efficiency of crosslink formation [2]. The use of zinc oxide as an activator is a standard procedure in rubber compounding, such as in utilization of cocoa pod husk and rubber seed shell as fillers in natural rubber compounds, in the Rheological and mechanical properties of natural rubber reinforced with agricultural by-product and in the investigation on the potential of rice husk ash as fillers for epoxidized natural rubber [3-6].

As activator the quantity of Zinc Oxide that is usually applied in formulations for various industrial and research purpose varies. This variation by various sources is without regards to desired properties that may be imparted into the vulcanizate either during 
processing, vulcanization or end product requirements.

The cardinal aim of this research was to identify study the effects of these variations on the mechanical properties of Natural rubber Composite.

\section{EXPERIMENTAL}

\subsection{Materials}

Natural rubber conforming to SNR-10was used in the study. Other compounding additives like sulphur, zinc oxide, stearic acid, MBT, CBS, TMQ etc. where of commercial grades.

\subsection{Sample preparation}

Mixing and homogenization of the rubber and compounding additives was done on a laboratory two roll mill (size $12 \times 38$ inches) with a friction ratio of $1: 1.5$ in accordance with ASTM D3184-89. The nip was adjusted to review the nip and more passes were done until a firm band was formed around the roll. The temperature of the roll was maintained at $60 \pm 5^{\circ} \mathrm{C}$ during mastication. The compounding ingredients where added as per sequence given in ASTM D3182. Before the addition of accelerator and sulphur, the batch was cooled. The compounded was further homogenized to obtain a through mix and finally sheeted out on a nip gap of $3 \mathrm{~mm}$. Mixing time and temperature were controlled during the entire process to avoid scorching or premature vulcanization.

Table1: Details of Applied Formulation

\begin{tabular}{l|c}
\hline Additives & phr \\
\hline Natural rubber (SNR-10) & 100.0 \\
Carbon black (HAF) & 40.0 \\
Sulphur & 3.0 \\
Zinc oxide & $0,2,3,4,5,6,7,8,10$. \\
Stearic acid & 2.0 \\
CBS $^{+}$ & 0.5 \\
MBT $^{++}$ & 1.0 \\
TMQ $^{*}$ & 0.5 \\
Process oil & 2.5 \\
\hline
\end{tabular}

+CBS= N-cyclohexyl-2-benzothiazolesulphenamide

$++\mathrm{MBT}=2$-Mercaptobenzothiazole

*TMQ=Polymerised,2,2,4-trimethyl-1,2-

dihydroquinoline

\subsection{Assessment of vulcanisate properties}

Vulcanisate properties such as Hardness, Tensile strength, Modulus Elongation at Break, Compression set and Abrasion resistance were assessed according to standard methods.(ASTM D1415,ASTM D1456,
ASTM D 385, BS 903 part A9, BS 903 part A6) respectively.

\section{RESULTS AND DISCUSSIONS}

\subsection{Tensile Strength}

Figure 1 shows that Tensile strength increases progressively with increase in Zinc Oxide level from 0 phr up to a maximum at5phr. This increase is attributed to consolidation of network structure of the rubber chains as a result of increase crosslink density [6]. Further increase in zinc oxide level was accompanied by a steady decrease in tensile strength. Heideman et al. [7] observed that the crosslink density increases with increasing zinc stearate concentration up to a level until reversion occurs which led to reduction in mechanical properties. Also Simpson, [7] asserted that all rubber compounds in which elemental sulphur is the crosslinking agent are subject to reversion usually manifested by reduced tensile strength and modulus. This trend was also observed by Chukwu et al. [8] in their independent work "effect of stearic acid level on the physical properties of natural rubber vulcanizate". The noticeable decrease in tensile properties at $6.00 \mathrm{phr}$ can equally be explained as reported by Samarzija-Jovanovic et al., [9] they postulated that the initial polysulphide crosslink formed from the conventional vulcanization system reacts further to form weak mono, di and cyclic sulphide bonds during vulcanization via the dissociation, recombination and rearrangement of the sulphure linkages. The above reactions are possible because the initial polysulphidic crosslinks formed are thermally unstable and hence undergoes homolytic scission of the sulphure bonds and thermal decomposition and desulphuration leading to weaker bonds. The above assertion had also earlier been made by Lewis, [10] in his seminal work "Vulcanizate structure and its effects on properties". As a result of the formation of these weaker bonds at higher stresses, these chains breaks and greater stress will be imposed on neighbouring chains with the eventual result of catastrophic rupture leading to decrease in tensile strength as the force increases.

There is increased reversion above 7.0pphr of Zinc Oxide level which is reflected in reduced physical properties such as tensile strength, elongation at break, modulus, and hardness [11]. In this study, we equally noticed the same phenomenon of reversion but at 5.0phr of Zinc Oxide level as reflected in reduced mechanical properties as can be seen in Figures 1, 2, 3, 4 and Figure 6 respectively. This assertion is also in agreement with [14] who studied 
the effect of replacing convectional Zinc Oxide with Nano-Zinc oxide, they found that maximum tensile properties were at 5.0pphr of conventional Zinc Oxide and 1.2pphr of Nano-Zinc Oxide level.

Below 5.0pphr $\mathrm{ZnO}$ level there is a noticeable decrease in tensile strength, elongation at break, modulus, hardness and even compression set; this is due to reversion as evidenced in reduced crosslink density leading to reduced physical properties.

\subsection{Elongation at Break}

Figure 2 shows that elongation at break decreases with increasing zinc oxide level. This observation is attributed to increase in crosslink density with increase in zinc oxide level as a result of consolidation of network structures. The reduction in elongation at break is due to stiffening of the polymer matrix as a result of high crosslink density formation and stiffening of the polymer chains leading to decrease in molecular chain mobility due to extensive formation of physical bonds in the polymer chain [10]. The decrease in elongation at break is as a result of corresponding increase in the efficiency of crosslink formation leading to less elastic material. Note that elongation is extension between benchmarks produced by tensile force [7].

\subsection{Modulus}

Figure 3 shows that Modules increase progressively with increase in zinc oxide level from $0 \mathrm{phr}$ to a maximum at 5.0phr. This observation is attributed to consolidation of network structure of the rubber as a result of increase in crosslink density as reported earlier. Further addition of zinc oxide after 5.0phr was accompanied by a steady decrease in modulus. This is as a result of reversion or over cure which as stated earlier results in reduction of some physical properties. At reversion there is reduction in crosslink density resulting in less stiff material.

\subsection{Hardness}

Hardness is determined by the amount and type of reinforcement, degree of dispersion and extent of crosslink density formation as a result of vulcanization [13]. Figure 4 shows that hardness increase with increase in Zinc Oxide level due to increase in crosslink efficiency and crosslink density formation. A number of studies on the activation process $[6,9,11,14]$ has revealed that an active sulphurating complex is formed by the reaction of $\mathrm{ZnO}$ and MBT to produce $\mathrm{ZMBT}$, which eventually is converted into the active sulphurating complexes that enhances the formation of more crosslink densities. The crosslink density increases with increasing zinc stearate concentrations up to a level till reversion occurs [15].

The above statement is very evident in this work; looking at the steady increase in hardness as a result of increased crosslink density up to a $\mathrm{ZnO}$ level of 5.0pphr, after which there is a steady decrease in hardness and other physical properties as a result of reversion. Hardness is a factor of crosslink density; the higher the crosslink density produced during vulcanization, the harder the material [17]. A higher crosslink density is the dominant factor for improvement in mechanical properties [18].

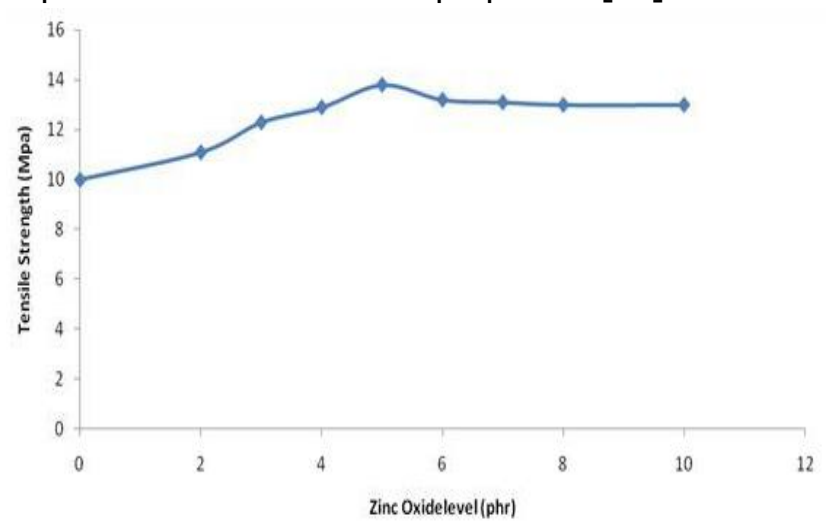

Figure 1: Effect of Zinc Oxide level on Tensile Strenght

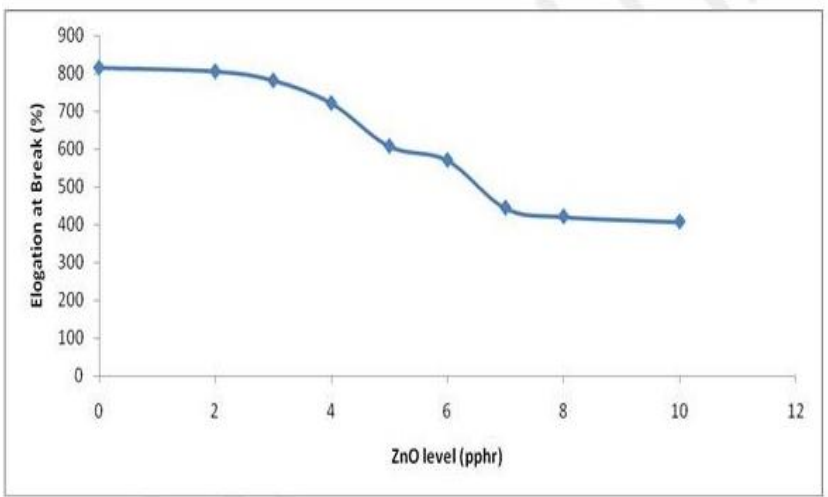

Figure 2: Effect of Zinc Oxide level on Elongation at Break

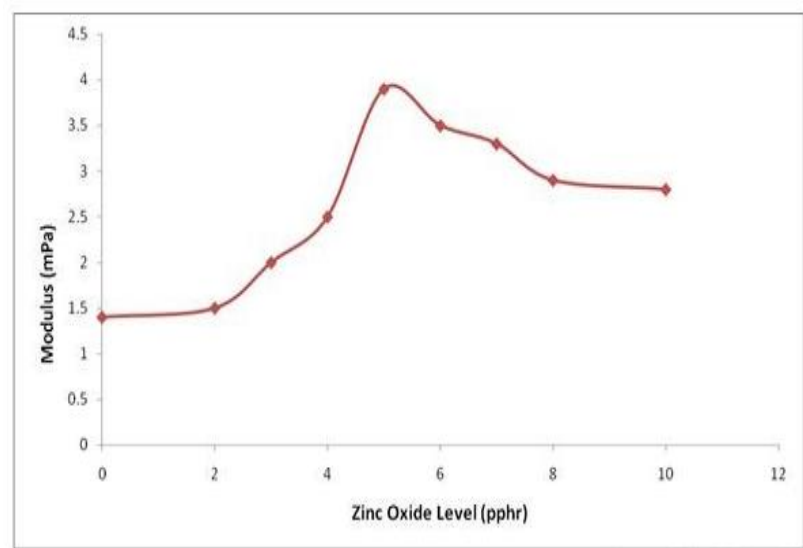

Figure 3: Effect of Zinc Oxide level on Modulus 


\subsection{Abrasion Resistance}

Abrasion resistance is the resistance of a rubber composition to wearing away by contact with a moving surface or an abrader [7].

From Figure 5, there is a reduction in the abrasion resistance as the zinc oxide level increases; this is as a result of the consolidation of network structures leading to increase in crosslink density formation which results to stiffer material. As the stiffness increases, there is the tendency to resist abrasion, hence the reduction in the abrasion resistance. But as the zinc oxide level increases to 4.0pphr, the elements of over cure or reversion started manifesting which is evidenced at 5.0pphr leading to less abrasion resistance, but after reversion the charred materials tend to act as reinforcement which result in further increase in abrasion resistance but not as efficient as that before reversion. Chukwu, et al [8] observed increased reversion above 7.0pphed which is reflected in reduced tensile properties. As a result of the loss of some physical properties due to reversion, the material losses some stiffness, it wears away on contact with a moving surface or an abrader leading to reduction in resistance.

But in terms of abrasion, above 7.0pphr the Zinc Oxide particles tend to act as filler particles in reinforcing the polymer matrix instead of an activator, hence the second phase of increase in abrasion resistance.

\subsection{Compression Set}

Compression set is a useful property of vulcanisates in predicting the service life performance where a rubber article is under load or a compressive force. A high percentage of compression set means high deformation, while lower compression set signifies low deformation [19].

The extent of compression set depends on temperature, the amount of load applied and the duration of the deformation. A low compression set at service temperature is an essential requirement for seals, O-rings and gaskets [20, 21].

If an elastomer is compressed under specified load and conditions, the residual decrease in its thickness after complete release of the compressive force is known as compression set [8]. It is important that compression set should be low for load bearing applications.

Figure 6 shows the effect of compression set on Zinc Oxide level. The Compression set increases as the level of Zinc oxide increases, until reversion occurs at 5.0pphr.

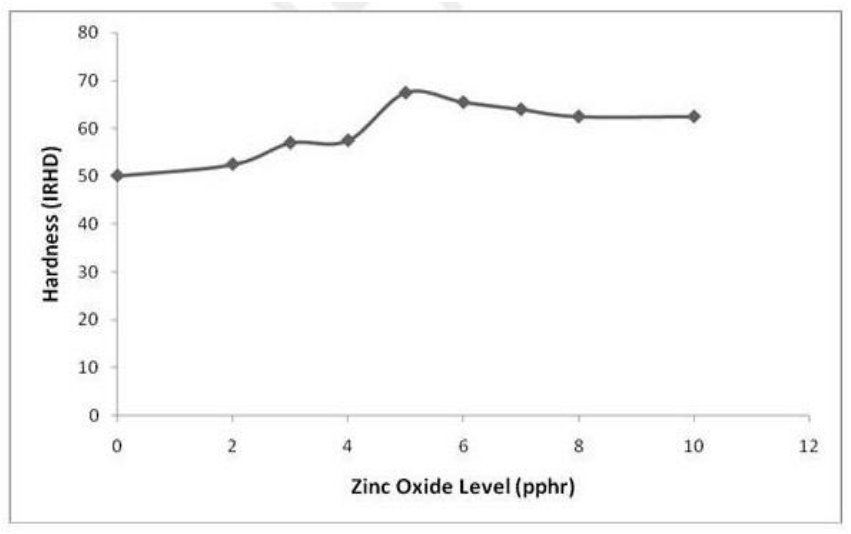

Figure 4: Effect of Zinc Oxide level on Hardness

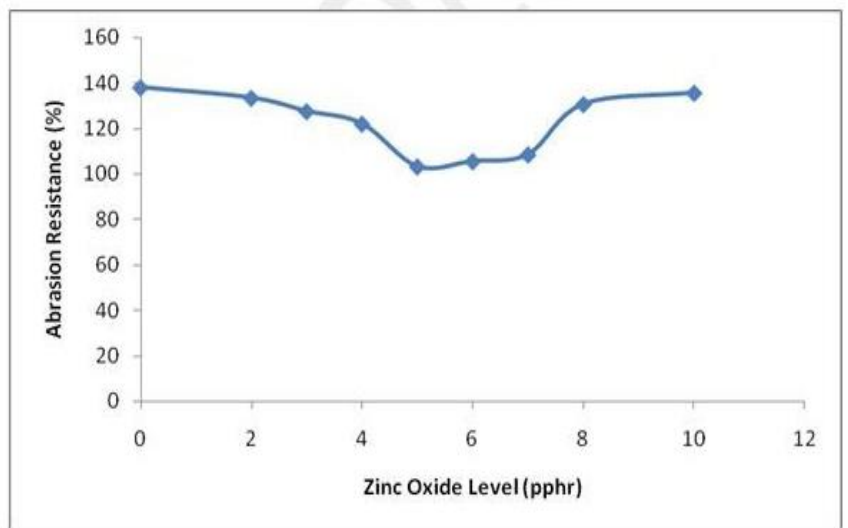

Figure 5: Effect of Zinc Oxide level on Abrasion Resistance

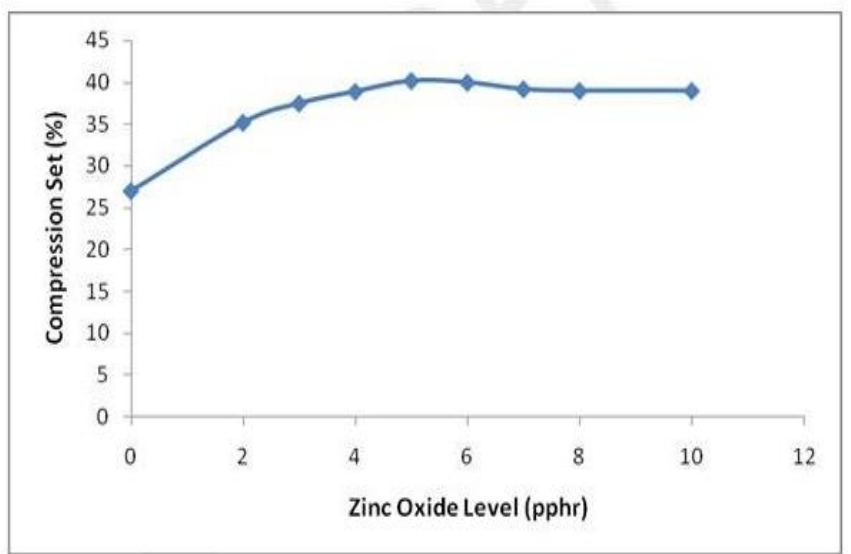

Figure 6: Effect of Zinc Oxide level on Compression Set

\section{CONCLUSION}

Each additive used in the formulation of a rubber compound has finite duty to perform either during processing, vulcanization or end product requirement of a particular compound. Hence, metallic oxide such as zinc oxide acts as activator. They are used in small proportion usually about $1.00-5.00 \mathrm{phr}$ to increase the efficiency of vulcanization or cross-linking.

It is advised from evidence obtained in this study that the level or quantity of Zinc Oxide used for the purpose of activation in rubber technology should be optimized based on performance and end-use application requirements. For the purpose of hardness and

Vol. 38, No. 2, July 2019678 
enhanced tensile properties, a known quantity of 5.0phr is recommended. Above this level there is noticeable reversion that occur which leads to reduction in hardness and tensile properties.

\section{REFERENCES}

[1] Hoffmann, W. Rubber Technology Handbook. CT.Ohio: Gardener/Hanser Publication. 1994 p. 56, Roger, B. Rubber Compounding. New York: Marcel Dekker p. 46.

[2] Imanah, J E; Okieimen, F E, Rheological and mechanical properties of natural rubber reinforced with agricultural by-product, Journal of Applied Polymer Science, volume 90, 2004: 3718-3722.

[3] Imanah, J. E. Okieimen F. E: Studies in the Mechanical Properties of Natural Rubber Reinforced with Agricultural by products. Proceedings of the 27th int'l conf. CSN September 10-15, 2004, 317-322.

[4] Ishak Z. A. M and Baker A. A, An investigation on the potential of rice husk ash as fillers for epoxidized natural rubber, European Polymer Journal, volume 31, number 3, 1995, $259-269$.

[5] Muhammed, S. Q., Alhumdany, A. A. and AlWaily, M. L: Effects of Nano-Zinc Oxide on Tensile Properties of Natural Rubber Composite. Kufa Journal of Engineering, volume 9, number 1, 2018.

[6] Heideman; G. Datta R.N; Noordermeer J. W. M; B. van Baarle, Influence of zinc oxide during different stages of sulfur vulcanization. Elucidated by model compound studies. Journal of Applied PolymerScience, 2005, 95 (6), 13881404.

[7] Simpson, R. Rubber Basics. London: Rapra Technology Ltd, 2002, p 60-65.

[8] Chukwu, M., Madufor, I. C., Ayo, M. D., Ekebafe, L. O. Effect of Stearic Acid level on the Physical properties of Natural Rubber Vulcanisate. The Pacific Journal of Science and Technology, volume 12, volume 1, 2011, $344-349$.

[9] Samarzija-Jovanovic, S., Jovanovich, V., Markovic, G., Zekovic, I and Marinovic-Cincovic, M. Propertiesr of Vulcanised Polyisoprene Rubber Composites Filled with Opalized White Tuff and Precipitated Silica. The Scientific World Journal, 2014, 344 - 352.
[10] Lewis, P. Vulcanizate structure and its effects on properties. Natural Rubber Technology, 17 (4), 1986. 57 - 65.

[11] Heideman, G.; Noordermeer, J. W.; Rabin N. Datta; Ben van Baarle, Effect of Zinc Complexes as Activator for Sulfur Vulcanization in Various Rubbers. Rubber Chemistry and Technology 2005, 78 (2), 245-257.

[12] Erman, B., Mark, J. E., and Roland, C. M. The Science and Technology of Rubber (Vol. 4). Tokyo: Elsevier, 2013, p 71-89.

[13] Heideman, G.; Jacques W. M. Noordermeer; Rabin N. Datta; Ben van Baarle, Various Ways to Reduce Zinc Oxide Levels in S-SBR Rubber Compounds. Macromolecular Symposia 2006, 245-246 (1), 657- 667

[14] Mati, M., Basak, G. C. and Srivastava, V. K. Influence of synthesized Nano-ZnO on cure and physico-mechanical properties of SBR/BR Blends. International Journal of Industrial Chemistry, volume 8, 2017, 273-283.

[15] Qi, Jy., Wu,Lx., and Zhuo, Dx. Preparation and properties of BR/SBR blends using surfacemodified nano-zinc oxide. Advance Materials Research, 910, 2014, 101-104.

[16] Sahoo, S., Maiti, M., Granguly, A., George, J. J., Bhowmick, A. K. Effect of zinc oxide nanoparticles as cure activator on the properties of Nitrile rubber. Journal of Applied Polymer Science, volume 105, 2017, 2407-2415.

[17] Surya, I., Ismail, H., and Azura, A. R.,. Alkanolamide as accelerator, filler dispersant and a plasticizer in silica-filled Natural Rubber Compounds. Polymer Testing, volume 32, number $8,2013,1313-1321$.

[18] Nagdi, K. Rubber as Engineering Material. Munich: Hanser, 1992, p 46-52.

[19] Scheirs, J. Compositional and Failure Analysis of Polymers: A Practical Approach. New York: John Wiley and Sons, 2000. 67-91.

[20] Hadi, F. A., Al-Azzawi, A. H., and Al-Allaq, A. A study on effect of Nano Zinc Oxide on Physical Properties of NR/SBR Composite. Journal of KufaPhysics, volume 7, number 1, 2015, 53-63. 